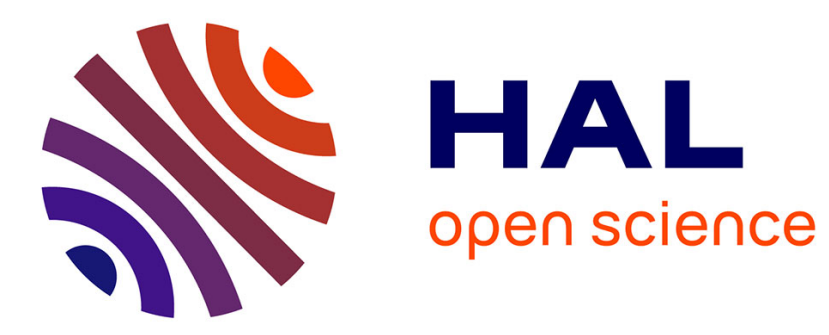

\title{
eHealth as the Trigger Initiative That May Foster Development in Health Care Delivery in Tanzania
}

\author{
Ernest Simon, Andrew Mushi
}

\section{To cite this version:}

Ernest Simon, Andrew Mushi. eHealth as the Trigger Initiative That May Foster Development in Health Care Delivery in Tanzania. 1st International Conference on Sustainable ICT, Education, and Learning (SUZA), Apr 2019, Zanzibar, Tanzania. pp.39-44, 10.1007/978-3-030-28764-1_6 . hal02515736

\section{HAL Id: hal-02515736 \\ https://hal.inria.fr/hal-02515736}

Submitted on 23 Mar 2020

HAL is a multi-disciplinary open access archive for the deposit and dissemination of scientific research documents, whether they are published or not. The documents may come from teaching and research institutions in France or abroad, or from public or private research centers.
L'archive ouverte pluridisciplinaire HAL, est destinée au dépôt et à la diffusion de documents scientifiques de niveau recherche, publiés ou non, émanant des établissements d'enseignement et de recherche français ou étrangers, des laboratoires publics ou privés. 


\title{
eHealth as the Trigger Initiative that may Foster Development in Health Care Delivery in Tanzania
}

\author{
Ernest Simon ${ }^{1}$ and Andrew Mushi ${ }^{2}$ \\ ${ }^{1}$ Ministry of Health, Community Development, Gender, Elderly, and Children \& Candidate, \\ MSc Leadership and Management Candidate, Mzumbe University \\ ${ }^{2}$ Dar es Salaam Campus College, University of Mzumbe, Dar es Salaam \\ saiernest4@gmail.com, amushi@mzumbe.ac.tz
}

\begin{abstract}
The Tanzania Ministry of Health, Community Development, Gender, Elderly, and Children developed eHealth Strategy aims to leverage the implementation of Information Communication Technology (ICT) in health service delivery [4]. The eHealth strategy in Tanzania was accord from the World Health Organisation after recognized the usage of ICT in supporting the delivery of health and health-related interventions [11]. The strategy promised various issues to be done by the Ministry in various capacities through its 16 Strategic Objectives (SO). Those promises were divided into four main categories of implementation which are eHealth Foundation with three SO, eHealth Solution with eleven SO, Change and Adoption with one SO, and lastly eHealth Governance with one SO. The implementation of eHealth initiatives has contributed tremendously to the changes and awareness of ICT in health services delivery in various capacities due to well-structured and adhering of the SO agreed on 2013. This has proven by changes of attitude for the health practitioners including doctors, nurses, administrators who are working to the health facilities in Tanzania. Clients who receive health care at health facilities are recognizing the importance of ICT in service delivery especially on reducing waiting time, and through the existing link between one department for example finance unit, medical record unit, and dispensing/pharmacy during the delivery of care to patients this link facilitate well-structured communication within the facility which smoothening the client/patients to practitioners interaction. Furthermore, it improved access of client information for the purpose of proper completion of a continuum of care to authorized practitioners within the facility.
\end{abstract}

Keywords: Health, Community Development, Gender, Elderly, Children, eHealth Strategy, Information Communication Technology

The implementation of eHealth initiative is accorded from various theories but the prominent one is the Unified Theory Acceptance and Use of Technology (UTAUT) which is a combination of various models which support the application of Information Communication Technology in service provision. Therefore this model 
borrowed constructs from each of the following models such as; Theory of reasoned action, the Technology acceptance model, the Motivational model. UTAUT is the key theory that supports the acceptance of ICT in service delivery. Venkatesh [1] identifies four key issues underpin the UTAUT which are performance expectancy, effort expectancy, social influence and facilitating conditions this issues have proven to have the close relation which influences the behavior of user to accept and use the ICT during delivering of services furthermore, issue like age, experience, and voluntariness have not left aside because it is believed to be moderators of technology acceptance and usage.

Therefore, for the successful usage of ICT, the human element should be taken into consideration and the user has to participate fully in organizing Information System in the organization to bring ownership and collective responsibility. It has been argued by Macleod [3] that, for successful implementation of any innovation including the use of ICT in service delivery user in the organization must be fully engaged in both hardware/software design with IT staff within the organization.

The implementation of ICT in health care delivery in Tanzania facilitated the Ministry to ensure that facilities are able to manage and identify the achievement of eHealth strategy implementation as follows; improved information sharing through Health Information Systems Integration to various partners, improved specialized health care services to patient in remote area using teleconsultation, facilitate early detection, rapid reporting and response via mobile platform, Strengthened Electronic Health Management Information System, improved resource management both human and financial and service delivery at health facilities, tracking of health commodities from Medical Stores Department to the facilities, Establishment of one source of facility register, improved network infrastructures to various Health facilities [5,6].

The Health Sector Strategic Plan 2015 - 2020 (HSSP IV) emphasised on the engagement of population in the modality of interactive communication through ehealth in order to establish the strong partnership between the government and community. This interactive communication is paramount important for the improvement of service delivery and is practically facilitated by the acceptability and usability of eHealth during the process of service delivery. The Ministry believed that the development and implementation of e-health strategy fostered usability of ICT hence improve service delivery in the country and contribute to the country development in terms of improving social services and will impact to the community at large [5,6]. Due to the anticipated result, the Ministry set the target that by 2020, all public hospitals in the country make use of ICT applications for administrative and medical processes [5,6].

Stakeholders in other sectors not limited to health services delivery can learn the effect of implementing eHealth initiatives in service delivery existing Tanzania particularly how service delivery was improved as a result of implementing eHealth which triggered client's satisfaction at the various level of care. ICT in Tanzania, like in other developing countries is an initiative that needs to be taken as a positive intervention to the social services (education, health, security, community development etc.) which involves clients or provider that are scattered and need to be 
coordinated for the purpose of delivered social services on time with little resources especially human resources.

The governance of health care delivery is done through various level of delivery from the national level to the community level. The Health Policy of 2007 and ehealth strategy has little described how this intervention may lead to the improving governance in health sector instead its emphases on integrating mushrooming of health information technology system in order to have one system which is interoperability within a sector [4]. Therefore, implementation of e-health strategy of 2013-18 is part of ongoing health sector reform in Tanzania which brings about a positive intervention to leverage governance in the healthcare industry which can be adopted and applied in delivery of service to the public.

The Ministry of Health, Community Development, Gender, Elderly, and Children established feedback mechanisms at health facilities whereby clients/patient after receiving healthcare service can provide opinions/claims through dialling a short code given by Tanzania Communication and Regulatory Authority (TCRA) *152*05*03\#. The feedback in terms of opinions/claims which was sent by the clients/patients is transmitted and analyzed through the web-based portal of www.maoni.moh.go.tz. This initiative of electronic feedback mechanism from the clients after receiving services is free of charge at the time of providing and has facilitated positive changes to the service provider hence improve service delivery. Immediately feedback mechanism from service user is paramount important as it indicates how the customer perceives the service provision. Stakeholders from different service provision authorities have to realize that direct electronic feedback mechanism from users can help to improve services when there is an integration of the system within the facility or at the point of delivery of the services.

The National guideline for integrated Health Facility Electronic Management Systems (iHFeMS) in Tanzania has indicated that all intervention regarding the usability of ICT is supposed to follow the e-health strategy [7]. It has been reported on Ministry's budget speech of 2018/19 that various public hospital from district hospitals to national level have managed to initiate a mechanism to collect revenue through e-electronics and some facilities have started to integrate patient records in an electronic system which helps to store and records of the patients information in a proper and accessible mechanism [10]. Furthermore, the introduction of Health Information Management System by the Ministry of health has facilitated the usability of District Health Information System 2 (DHIS2), Human Resources for Health Information System (HRHIS), Training Information Health System (TIHS), Emergence Information Diseases Severance Reporting (eIDSR). The Ministry is as the overseer of all eHealth initiatives implemented in a different level of care within the country.

Through the introduction of eHealth, Hospital Management Teams have managed to generate funds which are used on other interventions within the Hospital level and hence improve the quality of health provision. Doctors, nurses, administrators and other providers for health services are benefited in terms of receiving incentives due to the generated revenue which gave the morale to continue performing their duties. Therefore, this is the lesson to be learned to other stakeholders that it is paramount 
important to retain fund at the point of a collection as it is easier for the service provider to make rational decision on its allocation than been directed by higher authority also, it is a motivation for those who played a major role during its collection to be part of decision maker on how to utilize funds generated.

The current increased need for ICT in health has facilitated the Ministry of health to invest more on data quality management systems which facilitated an evidencebased decision as a compliment of the e-health strategy implementation. It was due to this fact the development partners have supported and facilitated the development of Tanzania Digital Health Investment Roadmap which is specifically for the investing on data systems and data use in order to strengthen the ability to make an evidencebased decision [8]. Therefore, it is important to adopt this investment roadmap as it outlines potential areas for investment and if well shared to the partners it may facilitate the institution to achieve the intended objective of providing quality service to the community.

Tanzania National Bureau of Statistics reported on 2018 that projected to be 89.2 Million in 2035 of which more than $60 \%$ are still estimated to reside in rural areas where are underprivileged with specialized medical care due to a low number of specialist in medical service provision or lack of equipment to provide high tech services. It have been reported by Ministry of Health that the shortage of healthcare provider is $52 \%$ whereas the available $48 \%$ also most of them are found in urban areas, according to Sikika [9] on their research report on "Tracking Study of Medical Doctors" identified that about $39.6 \%$ of tracked medical graduated are doing work that is not related to clinical practices. Therefore due to this scarcity of health practitioner to the rural areas telemedicine will provide alternative means for rural communities to access specialized healthcare services without traveling to the higher level facilities to seek for medical specialist or technology. Therefore, the scarcity of human resource is not the challenge only for health services provision but also the remarkable challenge has been reported in other sectors like education whereby the availability of teachers and instructors in rural area have still significant contribution to the performance of lower-level training facilities so the telemedicine initiative can be customized and contributed as part of solution to the community in need for quality provision of education services.

Furthermore, telemedicine as among initiative introduced by the country, the purpose of this initiative is to help the community to receive quality health regardless of the challenge existing of a shortage of human resources to the rural community. Therefore, this imitative of telemedicine in the country facilitated to foster the provision of telehealth services such as teleradiology, tele-oncology/telepathology, telecardiology to the areas where it was difficult to be offered especially to the rural areas which this service was not available. It is expected that telemedicine after its full implementation in the country it will ensure the wide scope of service delivery and hence the following impact will be realized to the community; to strengthening the provision of diagnostic, availability of specialized healthcare in under-served communities through the usage telemedicine due to the shortage of health practitioner at a lower level as it facilitates to have the ability to make consultations to the higher level facility connected to the network and hence improve delivery of services across 
the country. This initiative can be also implemented to social services sectors like education and the like as it capacitates lower level delivery unit to have a wide scope of delivery of services due to the fact that higher level is used as a backup where realized that needs arise.

The usage of the guideline and eHealth Strategy brought positive changes at facility level where curative services are delivered hence health facilities at the different level from Dispensary level to tertiary care facilities applies ICT in the delivery of health service in more than one department for Diagnosis purposes, drugs dispensing, revenue collection and billing system. The aim is that all activities within health facility should be integrated into the system which will make easier management performance of core and non-core function at the health service delivery at the health facility [2].

Implementation of eHealth and its performance are influenced by both internal and external factors of the organization this is infrastructures surrounding ICT implementation at the facility level such as connectivity of the internet, availability, and access of the device, privacy issues, and lack of sustainable power supply. This have been indicated by the study done in two region of Morogoro and Iringa by Busagala, L. et al [1] on the eHealth adoption in Tanzania which underlying the challenges facing both health workers and clients such as inadequate ICT skills, high cost of ICT in relation to economic status of community members, less developed infrastructure including lack of imaging equipment, small proportion of Internet users and lack of information about suitable ICT solutions. Therefore, for proper implementation of ICT in service delivery managers, Doctors, Nurses, and other key stakeholders should deal with those setbacks in order to influence smooth adoption and acceptability of ICT in developing countries like Tanzania.

It is recommended that the implementation of eHealth in developing countries in the health sector can be perceived as a trigger initiative that may foster development in healthcare delivery. The initiative uses information communication technology for its implementation, therefore, other sectors as an opportunity to learn the best practice of eHealth implementation in the health sector and customize it in order to fulfill the demand of improving service delivery to the intended user of the service which most of them are living in the unprivileged or rural areas.

\section{Reference}

1. Busagala, L.S.P. \& Kawono, G.C., (2013) 'Underlying challenges of e-health adoption in Tanzania', International Journal of Information and Communication Technology Research 3(1), 34-41

2. Eysenbach, G. (2007). Editorial: Poverty, Human Development, and the Role of e-Health. Journal of Medical Internet Research, 4, 34.

3. McLeod, L. Stephen, G. MacDonnell, and Bill, D. (2007). User participation in contemporary IS development: An IS management perspective, Australasian Journal of Information Systems, Volume 15(1).

4. MOH, (2013). Tanzania National eHealth Strategy 2013-2018, URT 
5. MOH, (2015). The Midterm Review Report of Health sector strategic plan III 2015, URT

6. MOH, (2015). Health Sector Strategic Plan July 2015 - June 2020 (HSSP IV): Reaching all Households with Quality Health Care. URT

7. MOH, (2016) Guideline and Standard for Integrated Health Facility Electronic Management Systems; Computerization of Health Facility Operation: Clinical, Administrative and Financial.

8. MOH, (2017). Journey to better data for better health in Tanzania based on Tanzania Digital Health Investment Road Map, URT.

9. Sikika, (2013). Where are the Doctors?-Tracking study of Medical Doctors; Retrieved on 2-Dec-18 Unpublished Document

10. URT, (2018). The Minister of Health budget Speech of the sector to the parliament for the financial year 2018/19.

11. WHO, (2012). International Telecommunication Union; National eHealth strategy toolkit.

12. Venkatesh, V., Morris, M.G., Davis, G.B., and Davis, F.D., User Acceptance of Information Technology: Toward a Unified View. MIS Quarterly, 2003. 27(3): p. $425-478$. 